Thorax, 1980, 35, 869-872

\title{
Effect of acute and chronic beta-blockade on carbon dioxide sensitivity in normal man
}

\author{
P F HUTCHINSON AND R N HARRISON
}

From the Faculty of Medicine, Southampton University Medical School, Southampton

ABSTRACT The effect of beta-adrenoceptor antagonists on the respiratory response to carbon dioxide rebreathing was studied in eight normal subjects. Propranolol, atenolol, metoprolol, and placebo were given in random, double-blind fashion. Subjects were studied before each treatment period, after one dose, and after eight days of treatment with each drug. A rebreathing method was used to produce progressive hypercapnia and the respiratory response was assessed by measuring minute ventilation and maximum rate of change of inspiratory mouth pressure. Beta-blockade was assessed by the reduction in heart rate during steady state exercise on a cycle ergometer. There was no change in the respiratory response to carbon dioxide after a single dose or eight days treatment of any drug. All three active drugs produced a significant reduction in exercise heart rate. The forced expiratory volume in one second was not altered by any of the drugs.

Beta-adrenergic antagonists are used extensively in clinical practice but can produce airway narrowing in susceptible patients, particularly those with asthma. ${ }^{1}$ The use of relatively cardioselective beta blockers may lessen the risk of bronchoconstriction but as some patients with airflow obstruction also have disordered ventilatory control, ${ }^{2}$ it must be established whether the respiratory effects of beta-adrenergic blockade extend beyond changes in pulmonary mechanics.

Mustchin et $a l^{3}$ observed that a single oral dose of propranolol markedly reduced the respiratory response to carbon dioxide rebreathing in normal volunteers, suggesting an effect on central control. Since a single dose of a non-cardioselective betablocker is unlikely to be given to patients at risk, we attempted to simulate the clinical situation by observing the effects of both acute and chronic beta blockade on ventilatory control. We used two widely prescribed cardioselective betablockers, atenolol and metoprolol, and compared them with a non-cardioselective drug, propranolol, in normal subjects. Metoprolol, a moderately lipid soluble drug, enters the central nervous system more readily than the water-soluble drug atenolol ${ }^{4} \mathrm{5}$ so the two drugs will not necessarily have similar effects on respiratory control.

Address for reprint requests: Dr RN Harrison, Department of Respiratory Medicine, Level D, Centre Block, Southampton General Hospital, Tremona Road Southampton SO9 4XY.

\section{Methods}

Six male and two female volunteers were studied. Their mean age was 22.5 years (range $19-33$ years). None gave any history of respiratory disease and all had normal spirometry. Two subjects smoked about 20 cigarettes per day. Informed consent was given and the study was approved by the local ethical committee.

Progressive hyperoxic hypercapnia was produced by a modified Read rebreathing method. ${ }^{6}$ Carbon dioxide was measured by an infrared analyser (PK Morgan capnograph) which we showed to have a highly linear response between 5 and $11 \% \mathrm{CO}_{2}$. A three-way valve enabled the subject to breathe from room air until he had settled on the mouthpiece and when ventilation was stable he was switched into a six-litre rebreathing bag initially containing a gas mixture of $5 \%$ $\mathrm{CO}_{2}$ and $95 \% \mathrm{O}_{2}$.

Ventilation was measured by displacement of air from a bag-in-box arrangement through an integrated pneumotachograph (Electrospirometer CS5; Mercury electronics). The maximum rate of change in inspiratory mouth pressure ( $\mathrm{dP} / \mathrm{dt} \max )$ was measured simultaneously with ventilation. Subjects breathed through a low resistance springloaded two-way valve (Morgan 71522) which produced a transient and imperceptible occlusion at the start of each inspiration. Mouth pressure was 
measured by a pressure transducer (UPI; Pye Ether Ltd). The signal was amplified, electrically differentiated (Robec 1141 differentiation amplifier) and displayed on a high frequency response recorder (Mingograf 34; Elema-Schonander). The calibration procedure as described by Matthews and Howell, ${ }^{7}$ was performed before each run.

Four-minute steady-state exercise tests were performed on an electrically braked cycle ergometer (Elema-Schonander). Work loads were chosen to give control exercise heart rates of more than $\mathbf{1 3 0}$ beats/minute in the last 30 seconds of exercise. Heart rate was determined from the electrocardiograph which was recorded using standard precordial leads and displayed on an ultraviolet recorder.

\section{STUDY DESIGN}

All subjects received an eight-day course of each of the following: propranolol $80 \mathrm{mg}$ daily; metoprolol $200 \mathrm{mg}$ daily; atenolol $100 \mathrm{mg}$ daily; placebo. The order in which the courses were given was randomised for each subject, identical tablets of propranolol, atenolol, and placebo were used with a non-identical standard commercial preparation of metoprolol (Betaloc, Astra). The study was designed to be double-blind.

Subjects were made familiar with the rebreathing procedure before entering the formal study. They were studied at the same time of day on the first and last day of each course. No coffee, tea, or nicotine was allowed on study days and tablets were taken on an empty stomach.

On the first study day subjects rested supine for 15 minutes before performing a rebreathing run followed by spirometry and an exercise test. The first dose of the tablet was given and two hours later after a further period of rest the three tests were repeated in the same sequence. They then took the tablets for seven days and on the eighth day returned to the laboratory to repeat the three tests two hours after that day's dose. A two-week wash-out period was allowed between courses.

The first rebreathing run in each course before any treatment acted as control and was compared with the $\mathrm{CO}_{2}$ responses after acute and chronic drug administration.

\section{DATA ANALYSIS}

All rebreathing traces were coded and read blind. Measurements of end-tidal carbon dioxide and minute ventilation were made every $20-30$ seconds and the corresponding values of $\mathrm{dP} / \mathrm{dt}$ max were taken as the mean of five breaths about a single $\mathrm{CO}_{2}$ point. Minute ventilation was converted to
BTPS and end-tidal $\mathrm{CO}_{2}$ expressed as partial 음 pressure.

A linear regression of both minute ventilation and $\mathrm{dP} / \mathrm{dt}$ max against $\mathrm{PCO}_{2}$ was determined by the method of least squares. Only values cor- ${ }^{\infty}$ responding to minute ventilation of greater than $\vec{\circ}$ $201 / \mathrm{min}$ were analysed to avoid the "dog-leg" of $\overrightarrow{\vec{\omega}}$ the lower end of the response curve.

The slopes and $x$-intercepts of the regression $\frac{\vec{x}}{x}$ lines after drug administration were compared $\underset{\omega}{x}$ with control values using Wilcoxon's signed rank test for paired data. Heart rates during exercise $\overrightarrow{.}$ and spirometry were compared using Student's $t$ o test for paired data. The reproducibility of the method from day to day was assessed by measuring 9 the coefficient of variation of the slopes of each $\vec{z}$ subject's four control rebreathing runs.

\section{Results}

There were no serious side-effects from any of the drugs although all subjects were able to identify $ळ$ active treatment periods by an increase in muscle. fatigue during the exercise tests. One subject withdrew for personal reasons before the completion of her final treatment period so the results for chronic metoprolol dosage are from seven subjects $\stackrel{0}{\circ}$ only.

Mean baseline data based on each subject's four $\overrightarrow{\vec{O}}$ control runs are shown in table 1 . The comparison 3 of control runs before starting a drug and subsequent runs after two hours and eight days of treatment is shown as pooled data for all subjects in table 2. No significant change was found in $\frac{\mathrm{O}}{3}$ either the slope or $x$-intercept of ventilation or $\stackrel{x}{x}$ $\mathrm{dP} / \mathrm{dt}$ max versus end-tidal $\mathrm{CO}_{2}$ for any treatment.

The within-subject day-to-day variability in the response to $\mathrm{CO}_{2}$ rebreathing was assessed as the $\frac{\mathrm{O}}{3}$ coefficient of variation of the slopes and inter-

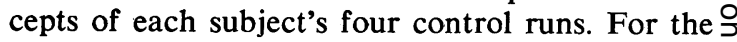

Table 1 Mean baseline values of carbon dioxide sensitivity, $F E V_{1}$, and exercise heart rate. The mean within-subject coefficients of variation (CV) are derived from each subject's four control runs

\begin{tabular}{lrr}
\hline Carbon dioxide sensitivity & $\begin{array}{l}\text { Group } \pm 1 S D \\
\text { mean }\end{array}$ & $\begin{array}{l}\text { Mean within- } \\
\text { subject } C V \\
(\%)\end{array}$ \\
\hline (i) Ventilation slope 1 min $^{-1} \mathrm{kPa}^{*}$ & $17 \cdot 58 \pm 5 \cdot 87$ & $27 \cdot 3$ \\
x-intercept $\mathrm{kPa}$ & $5 \cdot 25 \pm 0 \cdot 82$ & $7 \cdot 9$ \\
(ii) dP/dt max slope $\mathrm{kPa} \mathrm{sec}^{-1} \mathrm{kPa} \dagger$ & $0 \cdot 96 \pm 0 \cdot 33$ & $40 \cdot 3$ \\
X-intercept $\mathrm{kPa}$ & $5 \cdot 12 \pm 0 \cdot 61$ & $12 \cdot 3$ \\
FEV & $4 \cdot 33 \pm 0 \cdot 64$ & \\
Exercise heart rate & $148 \cdot 7 \pm 7 \cdot 04$ & \\
\hline
\end{tabular}

$* 1 \mathrm{kPa}=7 \cdot 5 \mathrm{mmHg}$

†multiply by $1 \cdot 3$ to give $\mathrm{cmH}_{2} \mathrm{O} / \mathrm{sec} / \mathrm{mmHg}$

tventilation or $\mathrm{dP} / \mathrm{dt}$ max is plotted on the $\mathrm{y}$-axis against end-tida! $\mathrm{CO}_{2}$ on the $\mathrm{x}$-axis. 
Table 2 Effect of the acute and chronic administration of propranolol, metoprolol, atenolol, and placebo on carbon dioxide sentivity, $F E V_{1}$, and exercise heart rate. Values are the mean for the group*

\begin{tabular}{|c|c|c|c|c|c|}
\hline & & Propranolol & Metoprolol & Atenolol & Placebo \\
\hline \multicolumn{6}{|l|}{ Ventilation } \\
\hline slope & $\begin{array}{l}\text { control } \\
2 \text { hours } \\
\text { 8 days }\end{array}$ & $\begin{array}{l}19 \cdot 33 \\
19 \cdot 17 \\
18 \cdot 20\end{array}$ & $\begin{array}{l}17 \cdot 15 \\
15 \cdot 89 \\
16 \cdot 58\end{array}$ & $\begin{array}{l}16 \cdot 34 \\
18 \cdot 54 \\
17 \cdot 09\end{array}$ & $\begin{array}{l}17 \cdot 53 \\
19 \cdot 56 \\
21 \cdot 09\end{array}$ \\
\hline $\mathrm{x}$-intercept & $\begin{array}{l}\text { control } \\
2 \text { hours } \\
8 \text { days }\end{array}$ & $\begin{array}{l}5.45 \\
5 \cdot 49 \\
5 \cdot 57\end{array}$ & $\begin{array}{l}4 \cdot 88 \\
5 \cdot 19 \\
5 \cdot 28\end{array}$ & $\begin{array}{l}5 \cdot 26 \\
5 \cdot 61 \\
5 \cdot 29\end{array}$ & $\begin{array}{l}5 \cdot 39 \\
5 \cdot 09 \\
5 \cdot 44\end{array}$ \\
\hline \multicolumn{6}{|l|}{$d P / d t \max$} \\
\hline slope & $\begin{array}{l}\text { control } \\
2 \text { hours } \\
8 \text { days }\end{array}$ & $\begin{array}{l}1.01 \\
0.96 \\
0.72\end{array}$ & $\begin{array}{l}0.94 \\
0.79 \\
0.74\end{array}$ & $\begin{array}{l}1.02 \\
1.02 \\
0.82\end{array}$ & $\begin{array}{l}0.87 \\
0 \cdot 88 \\
0.94\end{array}$ \\
\hline $\mathrm{x}$-intercept & $\begin{array}{l}\text { control } \\
2 \text { hours } \\
8 \text { days }\end{array}$ & $\begin{array}{l}5 \cdot 29 \\
5 \cdot 13 \\
4 \cdot 76\end{array}$ & $\begin{array}{l}4 \cdot 76 \\
4 \cdot 83 \\
5 \cdot 14\end{array}$ & $\begin{array}{l}5 \cdot 25 \\
5 \cdot 06 \\
5 \cdot 14\end{array}$ & $\begin{array}{l}5 \cdot 14 \\
4 \cdot 77 \\
4 \cdot 71\end{array}$ \\
\hline \multicolumn{6}{|l|}{$F E V_{1}$} \\
\hline & $\begin{array}{l}\text { control } \\
2 \text { hours } \\
8 \text { days }\end{array}$ & $\begin{array}{l}4 \cdot 36 \\
4 \cdot 31 \\
4 \cdot 32\end{array}$ & $\begin{array}{l}4 \cdot 32 \\
4 \cdot 23 \\
4 \cdot 30\end{array}$ & $\begin{array}{l}4 \cdot 28 \\
4 \cdot 27 \\
4 \cdot 23\end{array}$ & $\begin{array}{l}4 \cdot 37 \\
4 \cdot 35 \\
4 \cdot 28\end{array}$ \\
\hline Exercise he & $\begin{array}{l}\text { art rate } \\
\text { control } \\
2 \text { hours } \\
8 \text { hours }\end{array}$ & $\begin{array}{l}148.0 \\
114.6 \\
118.0\end{array}$ & $\begin{array}{l}148 \cdot 8 \\
111 \cdot 5 \\
105 \cdot 4\end{array}$ & $\begin{array}{l}143 \cdot 3 \\
111 \cdot 8 \\
109 \cdot 5\end{array}$ & $\begin{array}{l}149 \cdot 5 \\
147 \cdot 8 \\
146 \cdot 0\end{array}$ \\
\hline
\end{tabular}

*The eight day results with metoprolol are from seven subjects only. Full results are available from RNH.

ventilatory response slope this varied from $16.7 \%$ to $38.5 \%$ with a mean value of $27.3 \%$ (table 1 ).

There was a highly significant reduction in exercise tachycardia $(p<0.001)$ for all subjects on active treatment at both two hours and eight days and no effect from placebo (table 2). No drug caused any significant change in $\mathrm{FEV}_{1}$ (table 2) or vital capacity.

\section{Discussion}

This study has shown that acute and chronic administration of the beta-antagonists propranolol, atenolol, and metoprolol did not change the respiratory response to carbon dioxide in normal volunteers.

The single dose studies are in accordance with the results of Patrick et $a l^{8}$ who looked at propranolol and with Leitch et $a l^{9}$ who studied metoprolol and propranolol. This is the first report of the effects of chronic dosage and we believe it to be relevant to clinical practice since it approximates to the way in which the drugs are actually given, and because the effects of chronic treatment are not necessarily the same as those of a single dose. For instance, pretreatment with atenolol may enhance its central nervous system uptake, ${ }^{4}$ while the effects of the pharmacologically active metabolite of propranolol, 4-hydroxy-propranolol may be important after a single dose but are not seen when the drug is given for more than five days. ${ }^{10}$

We were unable to repeat the observations of Mustchin et $a l^{3}$ or support their conclusions that propranolol is a respiratory depressant. We are unable to explain this discrepancy although Mustchin $^{11}$ has himself emphasised the problems of using $\mathrm{CO}_{2}$ rebreathing as a pharmacological tool, predominantly because of its poor within-subject reproducibility. Some of the factors contributing to this variability, such as the recent intake of coffee or the performance of the tests at different times of the day, can be controlled. Despite attention to such details we still found large spontaneous within-subject variation in $\mathrm{CO}_{2}$ sensitivity between control runs, as illustrated by the large coefficients of variation (table 1). Studies during speech $^{12}$ and sleep ${ }^{13}$ suggest that influences from higher centres modify the ventilatory response to inhaled carbon dioxide; these cannot be fully standardised from one run to the next so that problems of reproducibility may be insurmountable

It is possible that small drug-induced changes in the response to $\mathrm{CO}_{2}$ may have been obscured by the overall noise of our method but this would not have obscured a change of the magnitude seen by Mustchin et al. ${ }^{3}$ They reported a mean reduction in the slope of ventilation versus end-tidal $\mathrm{CO}_{2}$ of $46.6 \%$ after a single dose of propranolol.

We assessed respiratory centre activity by $\mathrm{dP} /$ $\mathrm{dt} \max$ as well as minute ventilation since $\mathrm{dP} / \mathrm{dt}$ $\max$ is less likely to be influenced by mechanical changes in the lungs produced by beta-adrenergic blockade. In fact none of the drugs produced a change in spirometry so the failure of the drugs to alter the ventilatory response to carbon dioxide was mirrored by an unchanged $\mathrm{dP} / \mathrm{dt} \max$ response (table 2). Our spirometry results are consistent with previous studies showing propranolol to have no effect on airway resistance in normal man, ${ }^{1415}$ and with the view that bronchomotor tone in normal subjects is not under the influence of beta-adrenergic activity. Our results differ from those of Johnson and Clarke ${ }^{16}$ who showed that atenolol and metoprolol reduce the $\mathrm{FEV}_{1}$ in normal man.

All our subjects showed a highly significant reduction in exercise tachycardia after both two hours and one week of active treatment, confirming beta-adrenergic blockade. ${ }^{17}$ Although the study was designed to be double-blind, subjects were usually able to identify active treatment periods by the symptoms related to the exercise tests. The most common complaint was of increased lower 
limb fatigue and muscle ache during heavy exertion, which occurred in at least one of each subject's three active treatment periods. This appeared to be more severe with the two selective betablocking drugs but we made no formal attempt to quantify symptoms and do not claim that the drugs were given in equipotent doses. There were no other side-effects of note.

Studies with metoprolol and propranolol 1819 suggest that selective beta-blockers may be relatively safe in patients with airflow obstruction if there is no asthmatic component to their disease. As our results indicate that these drugs do not affect ventilatory control as assessed by $\mathrm{CO}_{2}$ rebreathing in normal subjects, we believe it is now necessary to examine the effect of their chronic administration to patients with fixed airways obstruction and this work is now in progress.

We thank Dr AE Tattersfield and Professor Howell for their help with these studies. ICI generously provided the propranolol, atenolol, and placebo tablets.

\section{References}

1 McNeill RS. Effect of a $\beta$-adrenergic-blocking agent, propranolol, on asthmatics. Lancet 1964; 2:1101-2.

2 Donald KW, Christie RV. The respiratory response to carbon dioxide and anoxia in emphysema. Clin Sci 1949; 8:33-44.

3 Mustchin CP, Gribbin HR, Tattersfield AE, George CF. Reduced respiratory response to carbon dioxide after propranolol: a central action? Br Med J 1976; 2:1229-31.

4 Bodin NO, Borg KO, Johansson R, Ramsay KH, Skanberg I. Tissue distribution of Metoprolol$\left(\mathrm{H}^{3}\right)$ in the mouse and the rat. Acta Pharmacol Toxicol 1975; 36: suppl 5:116-24.

5 Day MD, Hemsworth BA, Street JA. The central uptake of $\beta$-adrenoceptor antagonists. $J$ Pharm Pharmacol 1977; 29:52p.

6 Read DJC. A clinical method for assessing the ventilatory response to carbon dioxide. Australas Ann Med 1967; 16:20-32.
7 Matthews AW, Howell JBL. The rate of inspiratory pressure development as a measure of re- $\frac{\bar{c}}{\bar{D}}$ sponsiveness to carbon dioxide in man. Clin $S c i \underset{\widetilde{\alpha}}{\overparen{2}}$ Mol Med 1975; 49:57-68.

8 Patrick JM, Tutty J, Pearson JB. Propranolol and the ventilatory response to hypoxia and $\vec{O}$ hypercapnia in normal man. Clin Sci Mol Med $\stackrel{\circ}{-}$ 1978; 55:491-7.

9 Leitch AG, Hopkin JM, Ellis DA, Merchant $S, \stackrel{\omega}{\mathscr{\Omega}}$ McHardy GJR. Effect of propranolol and meto- $\vec{x}$ prolol on the ventilatory responses to carbon $\underset{\omega}{\times}$ dioxide and exercise. Chest 1978; 74:342.

10 Cleaveland CR, Shand DG. Effect of route of administration on the relationship between $\beta$ - $\dot{\infty}$ adrenergic blockade and plasma propranolol level. Clin Pharmacol Ther 1972; 13:181-5.

11 Mustchin CP. Carbon dioxide rebreathing and mouth occlusion pressure measurements. JR Coll $\vec{Z}$ Physicians Lon 1977; 12:87-95.

12 Phillipson EA, McClean PA Sullivan CE, Zamel $\mathrm{N}$. Interaction of metabolic and behavioural $\frac{\partial}{\square}$ respiratory control during hypercapnia and speech. $\stackrel{\mathbb{D}}{-}$ Am Rev Respir Dis 1978; 117:903-9.

13 Phillipson EA, Kozar LF, Rebuck AS, Murphy E. Ventilatory and walking responses to $\mathrm{CO}_{2}$ in . sleeping dogs. Am Rev Respir Dis 1977; 115: 251-9.

14 Richardson PS, Sterling GM. Effects of $\beta$ adrenergic receptor blockade on airway conductance and lung volume in normal and asthmatic $\frac{2}{\mathbb{D}}$ subjects. Br Med J 1969; 3:143-5.

15 Tattersfield AE, Leaver DG, Pride NB. Effects $\overline{\overrightarrow{0}}$ of $\beta$-adrenergic blockade and stimulation on normal human airways. J Appl Physiol 1973; 35: 613-9.

16 Johnson N McI, Clarke SW. The comparative effects of metoprolol and atenolol in healthy adults. Acta Therapeut 1978; 41:147-51.

17 McDevitt DG. The assessment of $\beta$-adrenoceptor $\stackrel{\circ}{\circ}$ blocking drugs in man. Br J Clin Pharmacol 1977; 4:413-25.

18 Tivenius L. Effects of multiple doses of metoprolol and propranolol on ventilatory function in 0 patients with chronic obstructive lung disease. Scand J Respir Dis 1976; 57:190-6.

19 Sinclair DJM. Comparison of effects of propranolol and metoprolol on airways obstruction $N$ in chronic bronchitis. Br Med J 1979; 1:168. 